The results of different statistical analysis (simple and multiple regressions, multivariate analysis according to the method of centred data) show that the improvement of conformation leads to an increase in the muscle to bone ratio and to changes in the muscle distribution (increase in the percentage of $M$. Semimembranosus, decrease in the percentage of thigh muscles). The variation of conformation thus appreciably modify the commercial and technological value of pork carcasses.

\title{
Objective method for measuring ham conformation
}

\author{
B. I. DUMONT, O. SCHMITT, T. BOUL,EAU \\ I.N.R.A., Laboratoive de Recherches sur la Viande \\ 78350 Jouy-en-Josas (lirance)
}

An objective method for measuring ham conformation in pigs is proposed. Carcasses were considered in internal-medial and in dorsal-medial views. Their images were recorded (by photography or by T.V. camera) and reproduced so that the limb length be the same for all animals. Variations in conformation were measured by quantifying the shape variations exhibited in relation to reference axis, by the outlines of the hindlimb. One of the axis goes from the hock tip to the anterior edge of the ischio-pubis symphysis, and the other represents the vertical axis passing through the hock tip.

Application of this method to a sample of pig carcasses of various conformations is described.

\section{Presence and distribution of giant muscle fibres in pig muscles}

\author{
O. SCHMITT, B. L. DUMONT \\ Laboratoire de Recherches sur la Viande \\ I.N.R.A., $7835^{\circ}$ Jouy-en-Josas (France)
}

The presence and distribution of giant muscle fibres (GF) were systematically explored in different muscles from four genetic types of pigs (Large White, French Landrace, Belgian Landrace and Pietrain).

The presence of GF was highly variable; some muscles did not include any and others up to some ten thousand. In some areas of the muscles these $G F$ represented up $5 \circ \mathrm{p}$. Ioo of the total number of the muscle fibres. GF were generally distributed around the muscle border. Within the muscle bundles they were nearly always located against the perimysium.

A map of the distribution of GF in different muscles was made. The presence of GF was marked in the hypertrophied types (Belgian Landrace and Pietrain). Increase in the number of giant muscle fibers is related to the rate of muscle hypertrophy. 